\title{
Analysis of The Influence of Graphic Financial Information Presentation; The Role of Human Information Modality, Experimental Approach
}

\author{
Reni Oktavia ${ }^{1}$, Edi Santoso ${ }^{2}$ \\ \{reni.oktavia@feb.unila.ac.id ${ }^{1}$,edi_santoso@gmail.com² ${ }^{2}$,
}

Faculty of Economics and Business, University of Lampung, Jl. Sumantri Brojonegoro, Bandar lampung, Indonesia ${ }^{1,2}$

\begin{abstract}
This study aims to examine the impact of presenting visual financial information on the quality of investment decisions in setting the stage of decision making that has time constraints. Experiments to test the effect of graphical and non-graphical information presentations are conducted with 52 experimental subjects. Based on the data generated in this research experiment, we can conclude that financial information presented in a graphical form provides a higher contribution to improve the quality of investment decisions than an ordinary table form. This study also finds that bar graphs are better used to present time series financial data than line graphs. In contrast, the research shows that personal information modality is statistically insignificant in influencing the quality of decisions. However, in this study, the low quality of visual modality decisions is higher than other information modalities. Finally, this study finds that information presentation format affects the human speed in understanding provided information that, in the end, also affects the quality of decisions made based on that information.
\end{abstract}

Keywords: Information graph, decision quality, information modality.

\section{Introduction}

The study of the decision-making process in the financial world is interesting, not only because it is complex and dynamic but also because it involves many phenomena and variables. Decision making is a process of identifying and selecting various solutions leading to the desired result [1], [2]

One model that is used to explain the decision-making process is Simon's Normative model. This model has identified the physical and psychological barriers faced by decision-makers in the decision-making process. Simon's Normative Model was developed based on the bounded rationality of decision-makers [2]. When processing received information, decision-makers are limited by their brain's ability to interpret and connect the meaning of collected information into a collection of alternative information solutions to the problems they face. It happens because, at the same time, their brain receives so much information that is both relevant to challenges they face and those that are not, so it raises an overload information phenomenon [3], which in turn can lead to poor quality decisions.

The use of graphics is not a new thing in the world of information systems. Many executives rely on the Graphics Design Department to produce quality graphics for presentation purposes in front of the board of directors, shareholders, banks, and products in front of large potential customers [4]. Graphs are intended to make the audience better understand the information to be conveyed. But the extent to which a figure can be an effective decisión aid, what factors influence it, as well as how a graph should be made and whether all graphic forms are suitable for all types of data are still big questions that require further research.

So the rapid development of the use of graphics has attracted many researchers in the field of information systems to investigate more deeply the effectiveness of the use of graphics in the decision-making process. However, from various studies used as references for this study, the results have not shown consistent results. Some studies, for example, by [5], and [6] show the results of using graphs more effectively compared to the use of temporary tables [7], [8], those produce conflicting conclusions. 
Psychological literature discusses a lot about how humans process the stimulus they receive from their surroundings. Although each researcher uses different terms to describe how human process stimuli obtained from the surrounding environment, it is generally agreed that there are two essential things in processing information in human, first how we absorb information readily (modality) and how we organize and process the information (brain dominance). Information modality and brain dominance, according to some experts, influence the human speed in processing the information they receive.

Based on the description above, this experimental study is conducted to test whether the presentation of financial information in accounting reports presented in graphical form (bar graph, line graph) and nongraph/table number) has a different effect on the quality of investment decisions, as well as comparing the level of the impact caused by graphic forms which are often used to present time series data, like Bar graph and Line graph on the quality of investment decisions. This researcher intends to test whether humans with specific information modalities have different responses to various forms of information presentation in investment decision-making situations that have time constraints.

\section{Literature Review}

\subsection{Theoretical Basis and Hypothesis Development}

Since humans do know, have limitations in processing information, providing additional information that is excessive (redundant) will reduce the ability of humans to understand a problem and reduce the effectiveness in making a quality decision [9] and [10]. Overload information phenomenon resulting from a combination of too much information received and the limited ability of humans to process information has prompted many parties to design a presentation display that is human friendly.

\subsection{Graphic and Decision Makers Productivity}

Graphs and tables are both decision aids that are widely used to present numerical information. Traditionally, a company's financial information is presented using meals as a tool for easy-understand readers. In recent years, information system designers have begun to switch to using various types of graphs in presenting financial information; even now, it is odd to read a prospectus or a financial performance report of a company that does not display charts.

But what exactly is the impact of using graphics on decision making and management productivity? Some studies produce findings that do not support the positive effects of graphs on the productivity of decision-makers [4]. Even research conducted by several researchers lately also still does not produce such a firm conclusion.

The purpose of using graphics in the delivery of information is to make the audience better understand the information. But the extent to which a graph can be an effective decisión aid, what factors influence it, and how to graph them and whether all graphs are suitable for all types of data are still big questions that require further research.

Subsequent studies in the domain of effectiveness in the use of graphs have sought to find answers to the many results of previous studies. Some researchers such as [11], [12], [13], [14], [13], [15] find that not all forms of presentation are suitable for all situations. From several studies, a new theoretical proposition emerged, namely Theory of Cognitive Fit, which was raised to explain a situation where each way of presentation would have excellent performance compared to the others depending on the conditions and characteristics of the information [10] and [16]. The theory explains that presenting something (using graphs or tables or something else) must use a strategy that matches the conditions in which the presentation is made. So the aim of increasing the ability to contribute to solving problems from the data presented is rising. 
Therefore, graphs based on the characteristics inherent to them, the graph will be appropriate when the data presented has a trend and is used to forecast future conditions, for this type of data the graph can better show a general picture and the relationship between the data presented. Conversely, the use of tables is beneficial if used on data that requires an emphasis on data values at a particular point in time and will be more useful to facilitate the explanation of data that have specific benefits [12], [17] and [18].

In a decision-making condition that does not have time constraints, the use of graphs and tables does not significantly impact the productivity of decision-makers [10], [19] and [20]. Therefore in this study, we propose that if the decision-making process involves forecasting trends in time-limited decision-making conditions. Managers who use charts as decision aids are expected to have better decision quality when compared to managers who use tables because by using trend charts and patterns of relationships between variables, it will be easier to understand than if the data are presented using graphs. Based on the description above, we hypothesized that:

H1: For investment decision-making processes that have a time constraint, Investors who are given information on the company's financial performance in the form of graphs will have a better investment decision quality compared to investors who have given financial performance information the type of number tables.

Besides testing the difference in the quality of decisions due to the use of graphs or tables. This study also tries to contribute by trying to examine the impact of the use of various types of graphs in this case bar graphs and line graphs on the quality of decisions. Base on The purpose of this second test on the proposition put forward by [21]. It states that decision makers can equip specific values from the data presented in the form of Bar graphs than the data presented in the form of Line graphs. Based on this proposal, we propose a hypothesis:

H2: For investment decision making processes that have a time constraint, Investors who are informed of the company's financial performance in Bar graph form will have a better investment decision quality compared to investors who are given financial performance information in the form of Line graphs.

\subsection{Information Modalities and Decision Quality}

Researchers in psychology find that humans tend to minimize cognitive efforts to achieve the accuracy of the decisions they make [17]. Several other studies have also found that managers take a lot of advantage from decision aids to reduce the effort needed to do a job ([22] and [11]. This study tries to learn more about whether the characteristics inherent in decision makers will also contribute to the quality of decisions made.

In the psychological literature, it is mentioned that the human style in absorbing information and processing information is a variable that influences a person in learning new information. By knowing someone's information modality, we can help them accelerate the understanding of the information we convey by providing a form of information presentation that matches the characteristics of the pattern they have. How to know the modality of someone's information, according to DePorter, can be simply seen from people's behavior when in daily life, when talking, reading, receiving a telephone, or when someone memorizes something. Deporter, in his book Quantum Learning, has mentioned the characteristics of specific modalities to assess the information modality of a person and has been widely used in determining the information modality of students in schools.

This guide will be used in this study to distinguish the information modalities of experimental subjects. And the results will be used to test whether people with specific information modalities impact the quality of decisions made in this study's experimental settings. Based on the proposition expressed by De Porter that human with visual modalities captures information quicker in the form of images and other forms of visualization than the human who has other modalities, we propose a hypothesis: 
H3: For investment decision making processes that have a time constrain, Investors who have a visual information modality will have a better investment decision quality if given financial information in graphical form compared to investors who have an auditory or kinesthetic information modality.

\section{Research Design}

\subsection{Experiments and Treatments}

The model of this research experiment is based on an experimental model conducted by Arunachalam (2002), who examines the impact of presenting visual information that is designed "Improperly" on the quality of decisions made. Our experiment is a one-shot case study because it does not use pretest or control groups. Each subject is required to rate, choose, and rank, which company has the best performance and is a profitable investment place based on the data we provide. The subjects in this experiment obtained six yearly data in time series in the form of total sales, income, and earnings per company from each company; in this study, it was assumed that earnings per share were entirely distributed as dividends to shareholders.

\subsection{Experiment Subject}

As a proxy for investors in this study, we use 6th-semester accounting students who are taking advanced financial accounting courses. For the researcher to believe that the experimental subject has sufficient knowledge about investment and is worthy of being an experimental subject, before entering the core experiment, the researcher will ask several questions about investment and accounting to ensure all preliminary items have the minimum level of knowledge needed to take part in the research.

\subsection{Experimental Procedure}

In this study, subjects were divided into three groups based on the treatment to be given. The three groups will be given their respective therapies in the form of company financial performance information for six years, the presentation of which is distinguished by each group, namely in the way of tables, bar graphs, and line graphs, different forms of display of information for each group of subjects constitute a form of treatment in this experiment.

In the process of making a decision, the experimental subjects were given only given 1.5 minutes to assess and select and rank which companies were the best based on the analysis they conducted on the data we provided. The time restrictions were also used to eliminate the effects of maturation. To avoid the learning effect, we designed three types of cases involving nine different companies, 9 of these companies were divided into three groups for each example. So in each case, subjects will be confronted with a different data set from the data in the other cases. To eliminate the impact of extraneous variables, the items in this experiment were chosen randomly. The granting of graphical and non-graphical information to the subjects was also done randomly, with minimized the hope that the influence of extraneous variables.

\subsection{Analysis Tool}

To distinguish the impact of using graphical and non-graphical information on the quality of investor decisions, we use the ANOVA test tool and the independent sample test difference test. ANOVA is used for several reasons including to test hypotheses 2 and 3 that have more than one independent variable and are categorical while the dependent variable is in the form of metrics based on this condition the researcher decides to use ANOVA. 


\section{Results of Analysis and Discussion}

Statistics Result of Independent Difference Test Sample Test To test the impact of providing graphical and non-graphical information on the quality of investment decisions. It has been stated in the analysis tool section that hypothesis 1 in this study was tested using the independent sample difference test. The results of the analysis for hypothesis 1 show that the average quality of investor decisions that get information in tabular form is 7.395 different from the quality of investor decisions that obtain graphical information with a mean of 12.31481 is statistically significantly different from P-Value $=0,000$. These results are confirmed with the results of research conducted by [5], [6], which state that the use of well-designed charts would make it easier to identify trends and relationships between variable. Hence, the use of charts is constructive in completing investment decision making that involves forecasting the future. Based on the data in this experiment, it can be concluded that financial information presented in graphical form has an enormous contribution to the quality of decisions than if presented in tabular form.

Before discussing the results of the ANOVA test, the homogeneity of variance test results with the Levene test shows that the resulting $\mathrm{P}$-value is $0.006(\mathrm{~F}=5,626)$. This indicates that the variance between groups is significantly different. This violates the assumptions needed by ANOVA, namely the similarity of variance between groups. However, this assumption violation is something that is not fatal, so that the analysis using ANOVA can be continued.

Output test between-subject effects show the F calculated result for an intercept of 804,900 with a P-value of 0,000 (Fcount 22,273) so that based on the data and experimental settings of this study, and it can be concluded that the presentation of financial information in different formats affects the quality of investment decisions. From the results of multiple comparisons analysis, it is also seen that the second hypothesis is supported, meaning that statistically it is understood that the average quality of investor decisions informed in the form of The bar graph is higher than that of investors who obtain line graphs with a mean value of 13.70370 and 10.98039 with $\mathrm{P}$-value $=0.013$. These results are consistent with the results of [21] research. They find that decision makers can quickly find specific values from data presented in the form of Bar graphs than data presented in the form of Line graphs. Based on our experiments, it can be concluded that bar graphs significantly contribute to the quality of decisions compared to line graphs in the presentation of time series data.

The results of the homogeneity of variance test with the Levene test show that the resulting P-value is 0.006 $(F=5,626)$. This indicates that the variance between groups is significantly different. This violates the assumptions needed by ANOVA, namely the similarity of variance between groups. While for hypothesis 3 , even though the average quality of investor decisions that have a higher visual modality compared to investors with other modalities, statistically, the difference is not significant $(P=0.128)$. This means that the third hypothesis does not have support.

\section{Conclusion}

Based on the discussion in the previous section, it can show that the presentation of financial performance information in the form of graphs affects and can improve the quality of decisions made by decision makers in a time-constrained decision-making situation. This Research confirms several studies conducted some previous researchers such as [21], [6], who state that the use of well-designed charts will make it easier to identify trends and relationships between variables, so the use of graphics is very helpful in completing work that involves future forecasting.

This study also produces the conclusion that bar graphs have a higher impact than line graphs on improving the quality of decisions when used to describe time-series data. The finding is consistent with the proposition raised by [21], which states that decision-makers can more quickly find specific values from the data presented in the form of Bar graphs than the data presented in the form of Line graphs. 
For hypothesis 3 , it is proposed to test whether the modality of human information influences the quality of the decision if the information provided is in graphical form. This result is different from the proposition submitted by De Porter, which states that people with visual modalities will more easily and quickly understand the information provided if the information is presented in graphical or other visualization forms. These results are different from the proposed theory, according to the analysis of researchers may be due to several things, namely:

1. The case design for this experiment visually does not consider color effects in graphic design, and graph coloring is a factor that can make graphs more easily understood by reader [4]. This may affect the speed of understanding the case given by subjects who have visual modalities.

2. Gradations and movements of financial performance that are used as a case for experiments visually are very easy to understand so that even if subjects are not included in groups that have visual modalities, they will quickly understand and make decisions based on performance graphs provided in the experiments.

\section{References}

[1] K. C. . and J. P. L. Laudon, Essentials of Management Information Systems, 10th Edition. 2013.

[2] R. Kreitner and A. Kinicki, Organisational Behaviour. 2010.

[3] A. G. Schick, L. A. Gordon, and S. Haka, "Information overload: A temporal approach," Accounting, Organ. Soc., vol. 15, no. 3, pp. 199-220, 1990, doi: 10.1016/0361-3682(90)90005-F.

[4] B. Ives, "Graphical User Interfaces for Business Information Systems," MIS Q., vol. 6, no. May, p. 15, 1982, doi: $10.2307 / 248990$.

[5] I. Benbasat, R. G. Schroeder, S. M. I. S. Quarterly, and N. Mar, "Experimental Investigation of Some Variables By : Izak Benbasat," MIS Q., vol. 1, no. 1, pp. 37-49, 1977.

[6] T. S. Tullis, "Evaluation of Alphanumeric, Graphic, and Color Information Displays.," Hum. Factors, vol. 23, no. 5, pp. 541-550, 1981, doi: 10.1177/001872088102300504.

[7] H. C. Lucas, "Experimental Investigation of the Use of Computer-Based Graphics in Decision Making.," Manage. Sci., vol. 27, no. 7, pp. 757-768, 1981, doi: 10.1287/mnsc.27.7.757.

[8] W. Remus, "Empirical Investigation of the Impact of Graphical and Tabular Data Presentations on Decision Making.," Manage. Sci., vol. 30, no. 5, pp. 533-542, 1984, doi: 10.1287/mnsc.30.5.533.

[9] "Load: The," vol. 55, no. 1, pp. 36-49, 2014.

[10] M. J. Eppler and J. Mengis, "The concept of information overload: A review of literature from organization science, accounting, marketing, MIS, and related disciplines," Inf. Soc., vol. 20, no. 5, pp. 325-344, 2004, doi: 10.1080/01972240490507974.

[11] I. Vessey, "Cognitive Fit: A Theory-Based Analysis of the Graphs Versus," Decis. Sci., vol. 22, no. 2, p. 219, 1991 , [Online].

Available: http://search.proquest.com/docview/198113450?accountid=10297\%5Cnhttp://metalib.dmz.cranfield.ac.uk:9003/ cranfield?url_ver=Z39.88-

2004\&rft_val_fmt=info:ofi/fmt:kev:mtx:journal\&genre=article\&sid=ProQ:ProQ:abiglobal\&atitle=Cognitive+Fit :+A+Theory-Based+Analy.

[12] I. Vessey, "The effect of information presentation on decision making: A cost-benefit analysis," Inf. Manag., vol. 27, no. 2, pp. 103-119, 1994, doi: 10.1016/0378-7206(94)90010-8.

[13] I. Vessey and D. Galletta, "Cognitive fit: An empirical study of information acquisition," Inf. Syst. Res., vol. 2 , no. 1, pp. 63-84, 1991, doi: 10.1287/isre.2.1.63.

[14] D. Fensel et al., Enabling semantic web services: The web service modeling ontology. 2007.

[15] A. Beaudry and A. Pinsonneault, "Understanding user responses to information technology: A coping model of user adaptation," MIS Q. Manag. Inf. Syst., vol. 29, no. 3, pp. 493-524, 2005, doi: 10.2307/25148693.

[16] S. Y. Chan, "The use of graphs as decision aids in relation to information overload and managerial decision quality,” J. Inf. Sci., vol. 27, no. 6, pp. 417-425, 2001, doi: 10.1177/016555150102700607.

[17] Z. Theocharis, L. A. Smith, and N. Harvey, "The influence of graphical format on judgmental forecasting accuracy: Lines versus points," Futur. Foresight Sci., no. July, p. e7, 2018, doi: 10.1002/ffo2.7.

[18] J. Recker, M. Rosemann, M. Indulska, and P. Green, "Journal of the Association for Information Systems Business Process Modeling- A Comparative Analysis * Business Process Modeling- A Comparative Analysis," J. Assoc. Inf. Syst., vol. 10, no. 4, pp. 333-363, 2009, [Online]. Available: http://aisel.aisnet.org/cgi/viewcontent.cgi?article=1501\&amp;context=jais.

[19] E. R. Iselin, "The effects of information load and information diversity on decision quality in a structured decision task," Accounting, Organ. Soc., vol. 13, no. 2, pp. 147-164, 1988, doi: 10.1016/0361-3682(88)90041-4.

[20] N. Goreva, E. Luther, and G. Bromall, "Issues in Information Systems EXPLORING ACCOUNTING 
INFORMATION SYSTEMS AND EMBEZZLEMENT FROM NONPROFIT ORGANIZATIONS Issues in Information Systems,” vol. 14, no. 2, pp. 39-46, 2013.

[21] J. K. H. Tan and I. Benbasat, "The Effectiveness of Graphical Presentation for Information Extraction: A Cumulative Experimental Approach," Decis. Sci., vol. 24, no. 1, pp. 167-191, 1993, doi: 10.1111/j.15405915.1993.tb00468.x.

[22] P. Todd and I. Benbasat, "Process tracing methods in decision support systems research: Exploring the black box," MIS Q. Manag. Inf. Syst., vol. 11, no. 4, pp. 493-512, 1987, doi: 10.2307/248979. 